\title{
NONUNIFORM ALONGSHORE SEDIMENT TRANSPORT INDUCED BY COASTLINE CURVATURE
}

\author{
A. López-Ruiz ${ }^{1}$, M. Ortega-Sánchez ${ }^{1}$, A. Baquerizo ${ }^{1}$, D. Navidad ${ }^{1}$ and M.A. Losada ${ }^{1}$
}

\begin{abstract}
This work proposes an expression for the alongshore sediment transport and a one-line type model to analyze the importance that the curvature of the shoreline and the bathymetric contours, and the associated alongshore wave energy gradients have in the evolution of the coastline and in the development of shoreline undulations. This model characterizes the alongshore wave energy gradients by means of the surf zone width variations and does not make any restriction on the shoreline curvature. The shoreline undulations of two different types of coast are investigated: a curvilinear coast in a prograding spit front, and an erosional stretch of coast adjacent to a river mouth. The results for the first one are in good agreement with observations. For the erosional coast good qualitative results are obtained, although a more intensive study is required.
\end{abstract}

Keywords: alongshore sediment transport; shoreline undulations; shoreline curvature

\section{INTRODUCTION}

The plan view of many sandy beaches is usually rectilinear or slightly curved. A change in the orientation of the beach planform, as it occurs at the tip of a spit (Figure 1),frequently leads to the development of morphologies such as shoreline undulations (López-Ruiz et al., 2012). These shoreline features have spatial dimensions of $10^{1}-10^{3} \mathrm{~m}$ and can propagate towards the tip of the spit (Petersen et al., 2008).

These oscillations can be observed on shorelines all over the world. For example, on Sylt Island in the southern North Sea (Germany) with dimensions of 500-1000 m (Figure 1a); at the spit on the west side of Cape Lookout (North Carolina, USA) with dimensions of 250-1000 m (Figure 1b); at the Arçay Spit (France) with lengths of 500-1000 m (Figure 1c); and at Sandy Hook Spit (New York, USA) with lengths of 1000-2000 m (Figure 1d).



Figure 1. Shoreline undulations on curved coastlines: a) Sylt Island Spit, Germany; b) Cape Lookout Spit, North Carolina, USA; c) Arçay Spit, France; d) Sandy Hook Spit, USA.

Examples of these undulations on the Spanish coast can be found at Doñana (Figure 2), at the mouth of the Guadalquivir Estuary (Gulf of Cádiz). These features have a wavelength $\lambda=500-2000 \mathrm{~m}$ and a crest-trough amplitude $a \cong 150 \mathrm{~m}$. The aerial photographs taken since 1956 (Figure 2), show that the undulations at the Doñana Spit are permanently present, although their location, shape, and

\footnotetext{
${ }^{1}$ Interuniversity Research Institute of the Earth System in Andalusia, University of Granada, Av. Del Mediterráneo s/n, Granada, 18006, Spain. alopezruiz@ugr.es, miguelos@ugr.es, abaqueri@ugr.es, dnavidad@ugr.es, mlosada@ugr.es
} 
dimensions may vary in time. Consequently, their generation and evolution are not linked to the occurrence of a single storm event.

Moreover, at Doñana spit, a wave climate analysis shows that the highest waves, responsible of the greatest changes in the shoreline, are not very oblique (Figure 2). Thus, the so called high-angle wave instability (HAWI) mechanism cannot explain the formation of shoreline undulations in the prograding front of the spit. Ashton et al. (2001) used this mechanism to explain the presence of sand waves on rectilinear coastlines, which are coastline features similar to shoreline undulations, as the result of an instability mechanism based on the coupling between littoral drift and coastal morphology induced by high-angle waves (offshore waves approaching at an angle greater than $43^{\circ}$ with respect to shoreline orientation).



Figure 2. Shoreline undulations observed in Doñana spit (Southern Spain) in 1956 (left panel) and 2007 (right panel). The local wave climate is shown in the right panel.

This example suggests that the formation and evolution of shoreline undulations with wavelengths on the order of $\lambda \cong 10^{1}-10^{3} \mathrm{~m}$ and amplitudes of $a \cong \lambda / 10$, are linked to shoreline contours with a conical bathymetry and sudden changes in orientation (Figure 1), as it occurs at the prograding front of spits.

These shoreline undulations can also be observed at beaches adjacent to river mouths. Figure 3 shows two different examples in the Southern coast of Spain where these features appear at the downdrift side of the river mouth (considering the main local littoral drift), where there is a net erosional rate and beach recession. The presence of a change in the mean shoreline alignment and a curvilinear bathymetry in the nearshore due to the river delta, suggests that the mechanism responsible of the formation of these undulations is the same as the one of the prograding spit fronts.

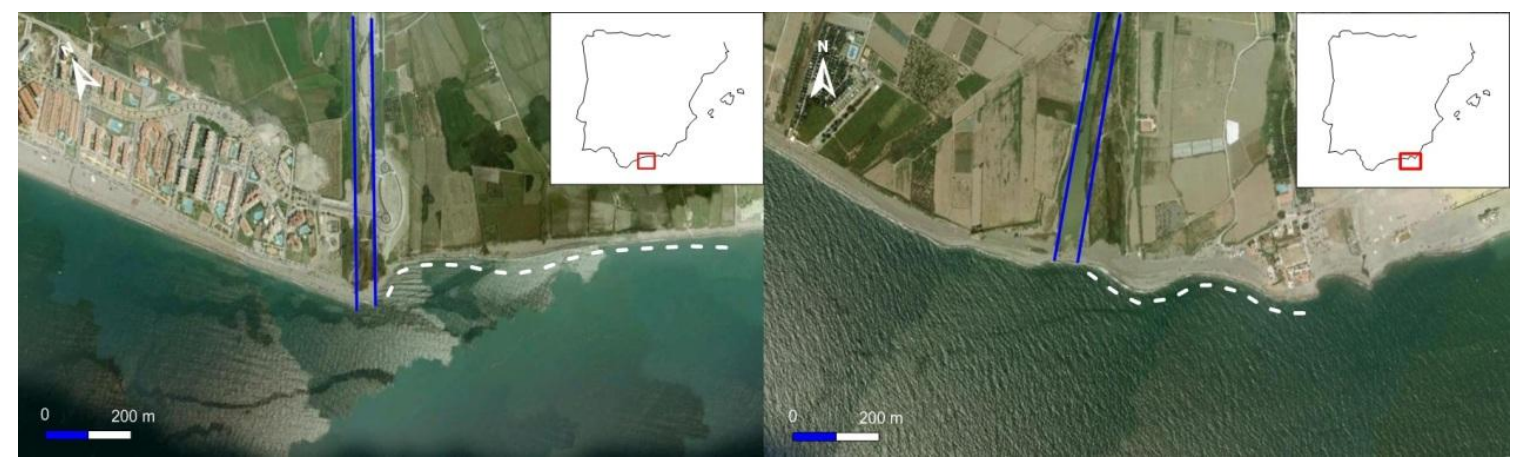

Figure 3. Shoreline undulations on erosional beaches adjacent to river mouths: Guadalfeo river mouth, Southern Spain (left panel); and Torre del Mar, Southern Spain (right panel).

The main objective of this work is to analyze the importance that the curvature of the shoreline and bathymetry, and the alongshore wave energy gradients have in the coastline evolution and the development of shoreline undulations. To achieve this objective, a one-line type model with a modified expression for the alongshore sediment transport is proposed. With this model the simultaneous effect of the local alongshore variation of wave energy (due to the morphology of the coastline) and the obliquity of incident waves is studied. The model takes into account the variation in the surf zone width caused by the convergence or divergence of the waves propagating over a conical bathymetry of small radius of curvature. The alongshore sediment transport formulation varies with the angle formed by the wave crests and coastline, with the surf zone width and with the across shore variation of the sediment 
grain size. This model focuses on the physical processes and complements previous experimental and numerical studies (Petersen et al., 2008).

\section{METHODOLOGY}

\section{Surf zone width gradients}

As waves approach the shore, they shoal and refract, typically reducing their speed (celerity) as their crests become more shore-parallel. There is a progressive increase in wave steepness and wave height/depth ratio until they eventually break onto the beach. As a result, the breaking wave angle and breaking wave height are interdependent. For straight coasts and small deep-water angles this phenomenon does not induce the appearance of new shoreline features. However, when waves approach with large deep-water angles, the phenomenon is particularly pronounced and may affect the coastline (Ashton and Murray, 2006a).

To properly characterize the wave energy variation along a schematic spit, the Delft3D Wave model was used to generate different cases of wave propagation over an idealized conical bathymetry. This model can perform SWAN model computations on curvilinear grids. The SWAN model is capable of simulating many complicated interactions and transformations experienced by waves propagating through space: refraction due to bottom and current variations, shoaling, blocking and reflections due to opposing currents, transmission/blockage through/by obstacles, effects of wind, whitecapping, depth induced wave breaking, bottom friction and non-linear wave-wave interactions. However, SWAN also has many limitations, one of which is that it cannot model reflection (Wood et al., 2001). The cases discussed in this paper experience little or no reflection, so according to this, the restriction is not important in this study. Hence, this model is therefore capable of accurately reproducing the phenomena under consideration, namely, shoaling and refraction that are dominant (Ashton and Murray, 2006a).

The shoreline was defined as a straight stretch of coast followed by a circular one with a radius of $2000 \mathrm{~m}$. The bathymetry was built using a constant beach slope value $\tan \beta=0.004$. The alongshore variations of the surf zone width were obtained for different combinations of the significant wave height, the peak period and the deep-water wave angle. The results show that the variable that defines the behavior of the surf zone width (and hence the alongshore variations of the wave energy) is the deep-water wave angle. Figure 4 shows the value of the non-dimensional surf zone width (the ratio between the obtained value and the corresponding to a rectilinear beach) against the non-dimensional value of the alongshore distance (the ratio between the alongshore distance and the length of the curvilinear coast) for a significant wave height of $H_{s}=2 \mathrm{~m}$, a peak period of $T_{p}=12 \mathrm{~s}$ and different deep-water wave angles.

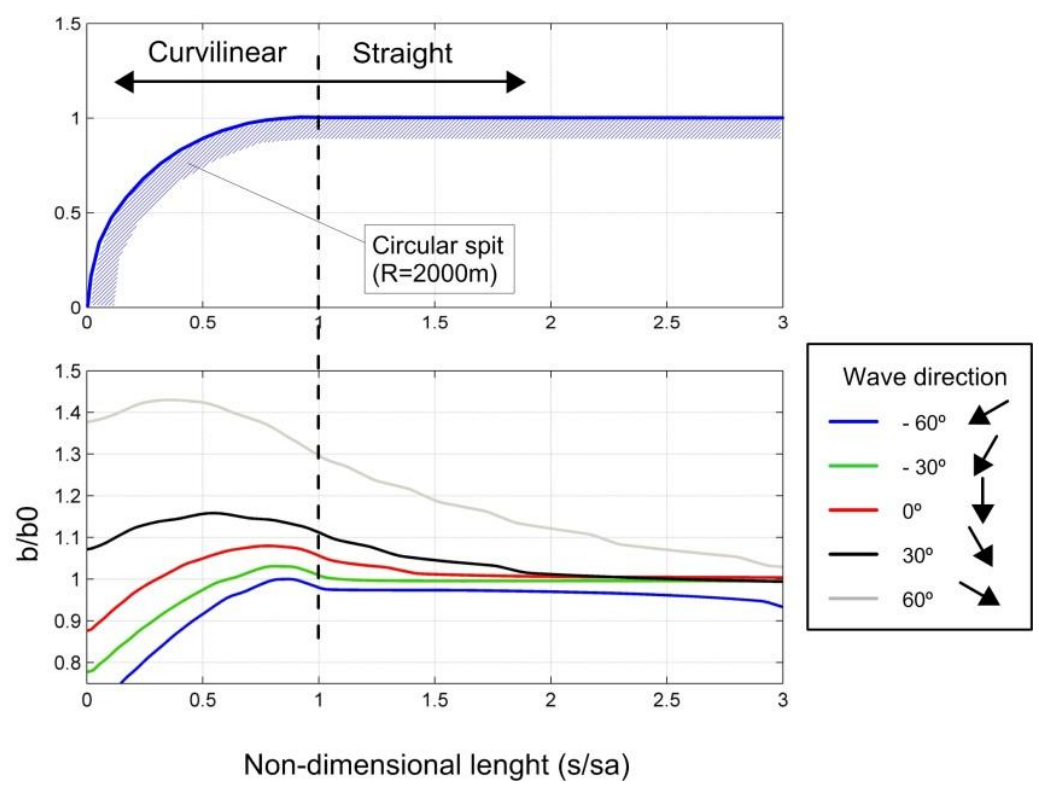

Figure 4. Variation of the surf zone width with the nondimensional alongshore distance, obtained from Delft 3D results for a theoretical spit front using a significant wave height of $H_{s}=2 \mathrm{~m}$, a peak period of $T_{p}=12 \mathrm{~s}$ and different deep-water wave angles: $\alpha_{0}=-60^{\circ}$ (blue line), $\alpha_{0}=-30^{\circ}$ (green line), $\alpha_{0}=0$ (red line), $\alpha_{0}=30^{\circ}$ (black line), and $\alpha_{0}=60^{\circ}$ (grey line). 
For waves approaching at high-angles (Figure 4, bottom panel), a progressive decay in the surf zone width towards the tip of the spit is observed. However, when waves arrive approximately normal to the rectilinear stretch, (i.e. with angles of incidence close to zero) or with negative values, the concentration of energy already observed by Petersen et al. (2008) produces a variation in the surf zone width that shows a maximum at the transition zone. The exact location where this maximum is attained depends on the angle of incidence. The same pattern was observed for the rest of the wave climate combinations propagated with Delft3D Wave model. This behavior of the surf zone width is schematized in Figure 5.

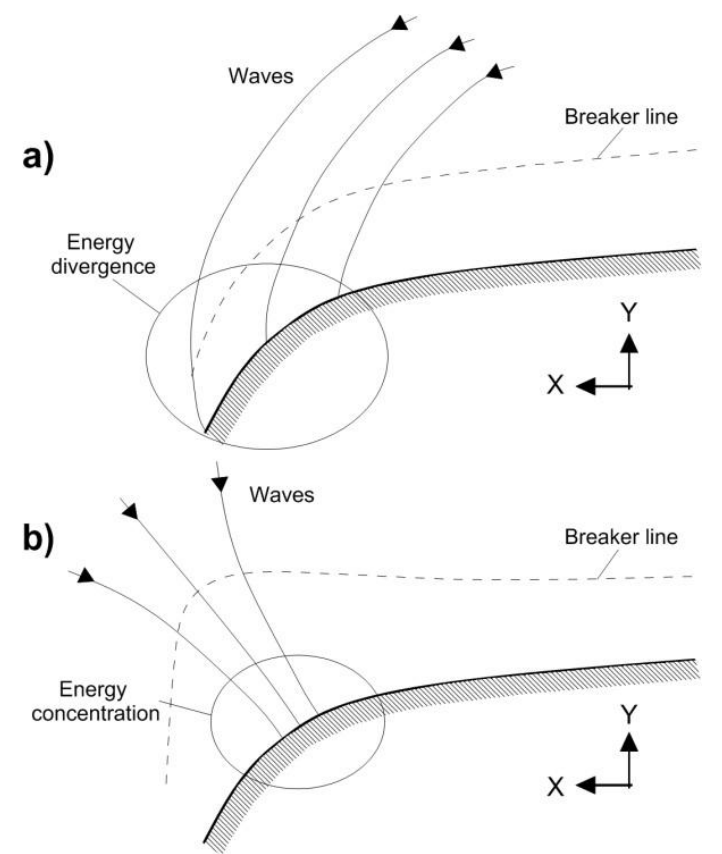

Figure 5. Wave energy pattern at the prograding front of a spit: a) energy divergence associated with highangle wave approach; b) energy concentration associated with normal to negative wave angle values (LópezRuiz et al., 2012). The angles of incidence are measured counterclockwise from the positive $Y$ axis.

\section{Alongshore sediment transport}

Once the existence of alongshore wave energy gradients has been demonstrated, the next step is to adapt the alongshore sediment transport formulation to curvilinear coasts. With that purpose, a curvilinear coordinate system $(s, y)$ is proposed (see Fig. 6) with $s$ parallel to the shoreline and $y$ perpendicular cross-shore. The surf zone width is denoted by $b$, and the angle between the wave crest and the shoreline, $\theta(s, y)$, is the sum of the wave angle, $\alpha(y)$, and the shoreline angle, $\phi(s)$. The value of the wave angle at breaking is $\alpha_{b}(s)$ and the alongshore current generated by the breaking waves is $V(y)$.

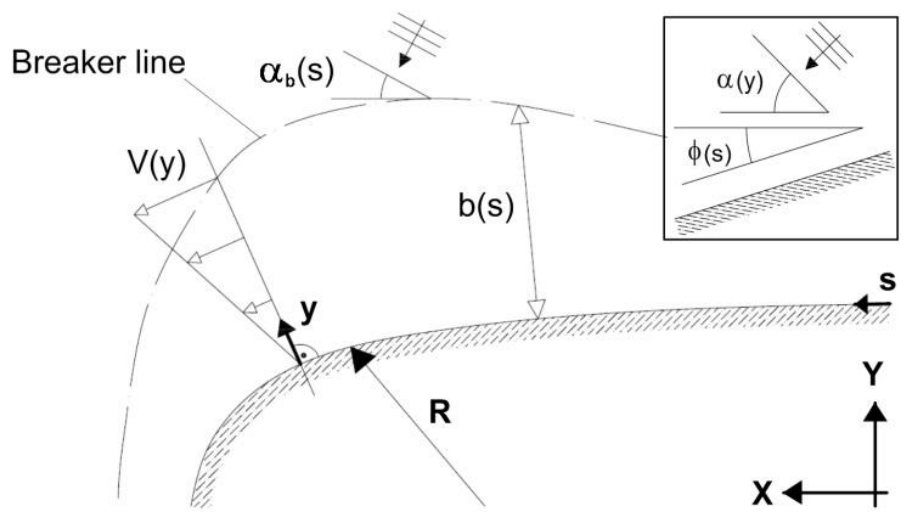

Figure 6. Proposed coordinate system for a curvilinear coast with a mean coastal alignment radius $\boldsymbol{R}$ (LópezRuiz et al., 2012). 
The hypotheses adopted for the analysis are the following:

1. The bathymetry is regular with a constant mean beach slope along the coast.

2. The significant wave height, $H(y)$, the alongshore component of the radiation stress, $S_{s y}(y)$, the wave energy, $E(y) C_{g}(y)$, and sediment size are continuous functions which vary monotonically in the cross-shore direction.

3. Snell law provides a good approximation to compute the refraction.

4. The turbulent diffusion is negligible.

Thus, if slope effects are ignored, the alongshore current generated by the breaking waves and its associated alongshore sediment transport are both parallel to the bathymetry.

Within this framework, the alongshore sediment transport expression of Inman and Bagnold (1963) has been modified to include the curvature effects which original expression is:

$$
S_{l s t}=\frac{K}{\left(\rho_{s}-\rho\right) g(1-p)}\left(E c_{g}\right) \cos \theta \frac{V}{u_{m}}
$$

where $S_{l s t}$ is the transport rate; $V$ is the alongshore current caused by the oblique incidence of the waves (Longuet-Higgins, 1970); $u_{m}$ is the maximum horizontal orbital velocity of the waves evaluated at the breaker zone; $\rho$ is the water density; $\rho_{\mathrm{s}}$ is the sediment particle density; $g$ is the acceleration of gravity; and $p$ is the porosity of the material. $K$ is a dimensionless coefficient that depends on the grain size. The sediment diameter variation throughout the beach profile is accounted for by using an expression for $K$ that varies cross-shore according to the formula of Del Valle et al. (1993). They found an exponential relationship between the coefficient in the CERC formula (USACE, 1984) and the sediment size represented by $D_{50}$. In order to obtain an analytical expression for the total sediment transport, $Q$, a linear law with the distance to the shoreline $y$ was adopted:

$$
K(y)=A_{1} y+A_{2}
$$

This choice is valid for small variations of $D_{50}$, for which the exponential law can be approximated with a linear function, after assuming a linear dependency of the sediment size on the distance to the shoreline. The angle formed by the wave crests and the coastline is defined as $\theta=\alpha+\phi$, where $\alpha$ is the angle of the waves and $\phi$ is the shoreline angle. The wave angle at breaking is $\alpha_{b}$ (Figure 6), and its value varies with $s$, since $b=b(s)$. This formulation accounts for the combined effect of waves and currents, where waves place the sand in motion and the alongshore current produces the net sand advection (Komar, 1998). The ratio $E c_{g} / u_{m}$ is proportional to the mean stress exerted by the waves, and the transport is in the direction of the alongshore current. In comparison with other empirical correlations based on wave power estimations, this equation comprises more fundamental processes.

The total sediment transport parallel to the coastline is obtained by averaging Eq. (1) per unit surf zone width:

$$
Q(s)=\frac{1}{b(s)} \int_{0}^{b(s)} S_{l s t}(s, y) d y
$$

The integral has an analytical solution and the following expression for (3) can be obtained:

$$
Q(s)=P_{1}(b(s)) \cos (2 \phi(s))+P_{2}(b(s)) \sin (2 \phi(s))
$$

where $P_{l}(b(s))$ and $P_{2}(b(s))$ are two polynomial functions dependent on the surf zone width and on the characteristics of deep-water waves. Thus, the total alongshore sediment transport expression is a function which amplitude depends on the surf zone width and which wavelength depends on the shoreline angle. Notice that no restrictions have been done on the curvature of the coastline.

\section{One-line type model}

The temporal evolution of the shoreline is obtained from the equation of conservation of sediment that reads:

$$
\frac{\partial \eta}{\partial t}=-\frac{1}{D} \frac{\partial Q}{\partial s}
$$


where $\eta(s, t)$ is the shoreline position, $t$ is time and $D$ is the closure depth. Eq. (5) is solved for the term $Q$ given in Eq. (4) and Neumann-type boundary conditions, with a finite differences numerical scheme. Applying the chain rule to the resulting equation, the following expression is obtained:

$$
\begin{aligned}
\frac{\partial \eta}{\partial t}= & -\frac{1}{D}\left[\left(P_{1}(b(s)) \cos (2 \phi(s))-P_{2}(b(s)) \sin (2 \phi(s))\right) \frac{\partial \phi}{\partial s}+\right. \\
& \left.+\left(\frac{\partial P_{1}(b(s))}{\partial s} \cos (2 \phi(s))-\frac{\partial P_{2}(b(s))}{\partial s} \sin (2 \phi(s))\right) \frac{\partial b}{\partial s}\right]
\end{aligned}
$$

This result shows that the diffusivity depends on $b(s)$ and $\phi(s)$, which are the main inputs of the model, and their respective gradients. The first term in the right hand side is proportional to the curvature of the coastline and the second term includes the effect of the variation of energy conditions along the coastline. The former dependence is similar to the one previously obtained by Ozasa and Brampton (1980), whereas the latter dependence resembles the one given by Ashton and Murray (2006a).

\section{APPLICATION AND RESULTS}

\section{Prograding spit front: Doñana spit}

First, the model was applied to the ideal shoreline presented in Fig.4 with the same dimensions that the prograding front of Doñana spit, with a surf zone slope $\tan \beta=0.004$ and sediment size $D_{50}=0.17$ $\mathrm{mm}$. Due to the dimensions of the spit, at least a few years of climate forcing are required for the undulations to develop. Accordingly, we analyzed the evolution of the shoreline position after five years of wave climate forcing with the methodology by Baquerizo and Losada (2008), using as a morphodynamic tool the proposed one-line type model (Eq. 5).

This procedure considers that the wave climate during a certain period of time can be described as a succession of sea states. Assuming that the morphological changes are cumulative processes, in the sense that the response to a certain sea state is the initial condition to the next state action, it is possible to imitate the process for a given realization of the wave climate. The model is launched with the first state and the initial condition. The cumulative action of the sequence of states is then accounted for by subsequently applying the one-line model along with the prediction made in the previous state as an initial condition. Repeating this process a large number of times, $N=100$, a sample with $N$ equally likely outcomes of the shoreline position after five years of climate forcing. This sample is then analyzed with probabilistic techniques.

The realizations of the climate forcing were obtained with the methodology devised by Solari and Losada (2011) using data obtained at hindcasting point WASA14718 $\left(36.5^{\circ} \mathrm{N}, 7^{\circ} \mathrm{W}\right)$, provided by Puertos del Estado (Ministry of Public Works, Spain). This methodology uses to simulate the significant wave height $H_{s}$, a non-stationary parametric probability model that describes seasonal variability and a copula-based model for time dependence (Solari and Losada, 2011). The corresponding wave peak period and mean direction were then obtained with a Vector Autoregressive (VAR) model on the basis of the simulated wave height and the available wave climate data.

The wave climate forcing was provided to the model as a series of three-hour sea states. According to the results obtained with Delft 3D, already commented in the Methodology Section, for each sea state, the surf zone width was considered to be proportional to the significant wave height with the shape that corresponds to the incoming wave direction. It was assumed that during a sea state, the possible changes in bathymetry did not significantly affect wave propagation.

Fig. 7 shows the mean position of the shoreline and some of the shorelines obtained after 2.5 years of climate forcing (left panel), that is, halfway the entire period of time of simulation, and after the 5 years (right panel). As can be observed, undulations begin to develop on all of the shorelines in almost fixed positions. The first undulation is located between alongshore positions $1000 \mathrm{~m}$ and $2500 \mathrm{~m}$ in the region closest to the prograding front and the second one between positions $2500 \mathrm{~m}$ and $3000 \mathrm{~m}$. At the end of the simulations, the undulations are more pronounced although they remain in the same position. The wavelengths of these features are also almost deterministic with values $\lambda_{1} \approx 700 \mathrm{~m}$ and $\lambda_{2} \approx 2000$ $\mathrm{m}$. Their amplitudes show, however, certain variability. They range approximately between $110 \mathrm{~m}$ and $160 \mathrm{~m}$ for the first one and between $10 \mathrm{~m}$ and $50 \mathrm{~m}$ at the front part, as can be observed in Fig. 8 that plots their respective distribution functions. 

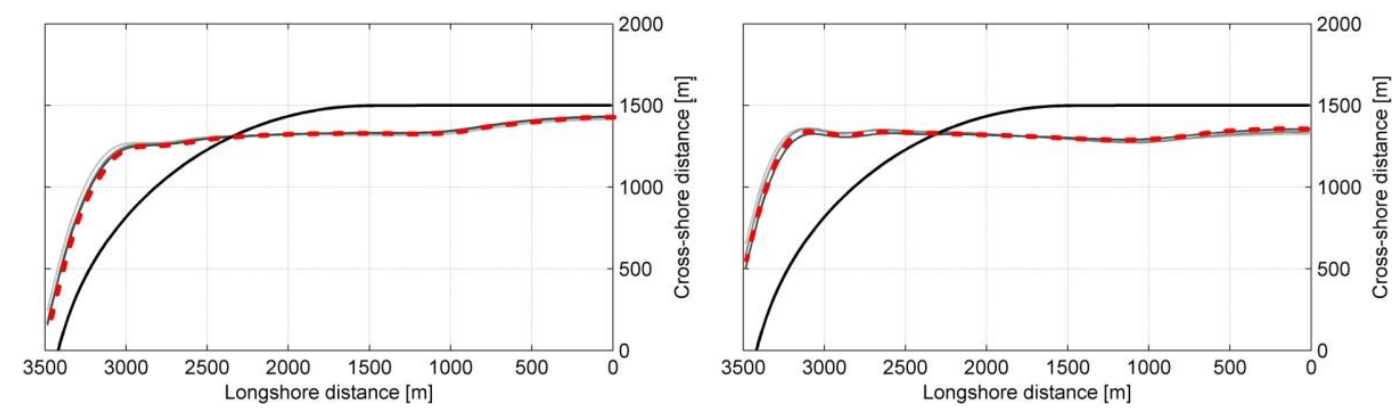

Figure 7. Some of the final shorelines (solid grey lines) and mean shoreline (red dashed line) for the Doñana spit after 2.5 years of wave climate forcing (left panel) and after 5 years of wave climate forcing (right panel). The black line represents the initial shoreline.
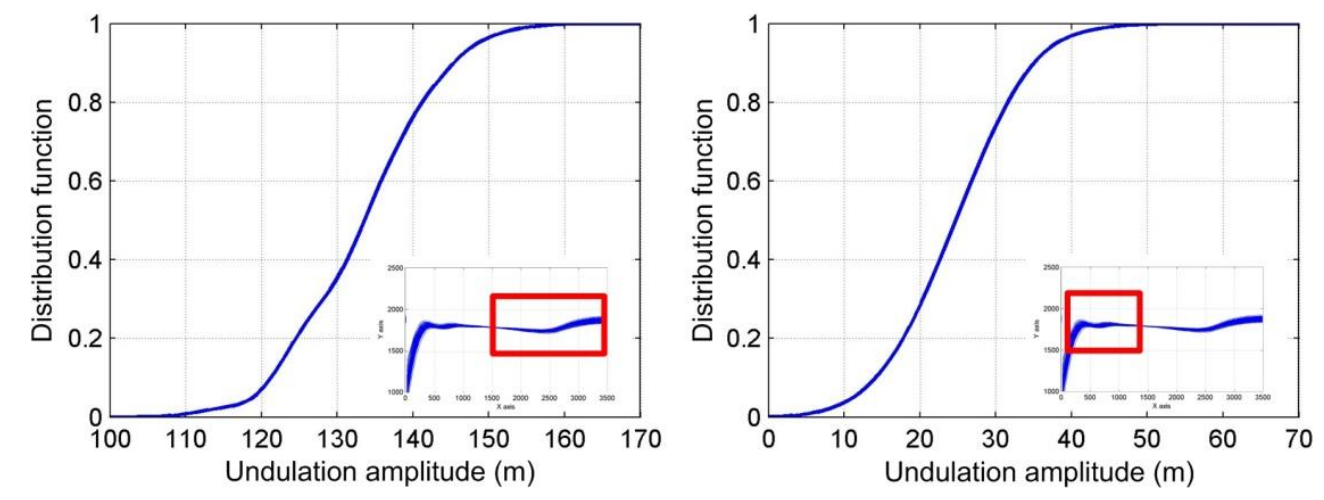

Figure 8. Probability distribution functions of the amplitude of the undulations after 5 years of climate forcing.

This sequence of erosion-sedimentation stretches is similar to that obtained in laboratory experiments by Petersen et al. (2008) and to those observed at the Sylt spit (Figure 1a). At the end of the simulations, the shoreline undulations are more pronounced although they remain in the same alongshore position (Figure 7, right panel).

Figure 9 shows in red some of the 100 final outcomes of the model simulations after 5 years over an aerial photograph of Doñana Spit taken in 1956, before the intense human interventions in the estuary (Díez-Minguito et al, 2012). The mean shoreline position observed is also presented (white dashed line). These results show that the locations, the lengths and the amplitudes of the shoreline undulations are very similar to the observations.

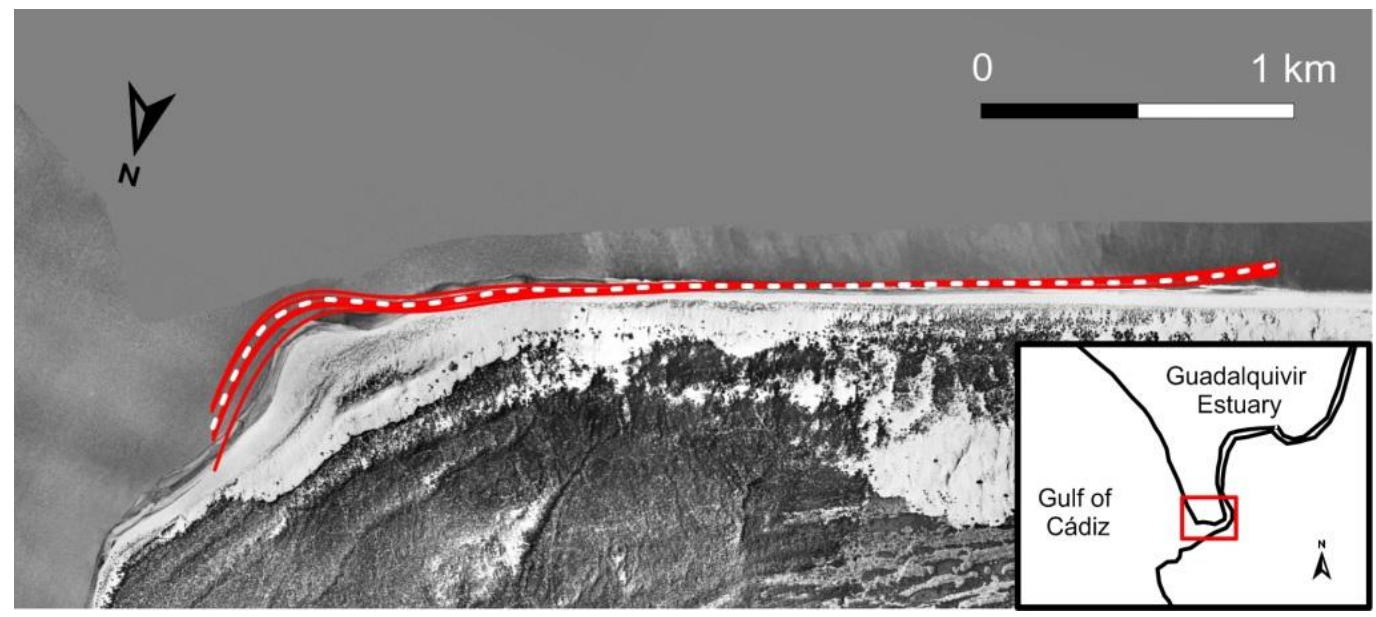

Figure 9. Some of the simulated shorelines (red lines) and the mean shoreline position (white and dashed) shown over an aerial photograph taken in 1956. Erosional coast adjacent to a river mouth: preliminary results of the Guadalfeo river mouth 
Preliminary results of the model were also obtained for an erosional coastal stretch of a beach adjacent to the Guadalfeo river mouth, located in Southern Spain. This beach has a curvilinear nearshore bathymetry (Figure 10) due to the deposition of the Guadalfeo river sediment that took place mainly before the construction of dam in the river basin in 2004. The weak sediment contribution of the river after that time, and the channelization of its mouth that acts as a barrier for the alongshore sediment transport, have produced during the last years, severe erosion in the downdrift part (right side in Figure 10). Available aerial images of this stretch of the beach frequently show shoreline undulations with wavelengths $\lambda \cong 250 \mathrm{~m}$, appreciably smaller than the features observed at Doñana spit.

To analyze the role that the curvilinear bathymetry and the presence of a barrier in the alongshore sediment transport play in the development of shoreline undulations in this type of coast, the one-line type model was applied to a straight coast with two dikes that do not allow sediment transport to occur from one side to the other. For the wave forcing, Delft 3D Wave propagations were carried out using the real bathymetry of the study zone (Figure 10). The results show that the concave-type nearshore bathymetry produces a wave energy concentration downdrift the river mouth (considering the direction of the main littoral drift, see Figure 11).

The one-line type model developed is forced with the surf zone width obtained from Delft3D propagations. Figure 11 presents the results after three months of predominant wave forcing and shows the formation of shoreline undulations in the downdrift part of the beach, as well as the accretion of the updrift part. Results are qualitatively in agreement with the observations. However, a more intensive analysis that includes the variability of the wave climate is necessary to properly validate the simulations and to obtain more accurate values of wavelengths and amplitudes.

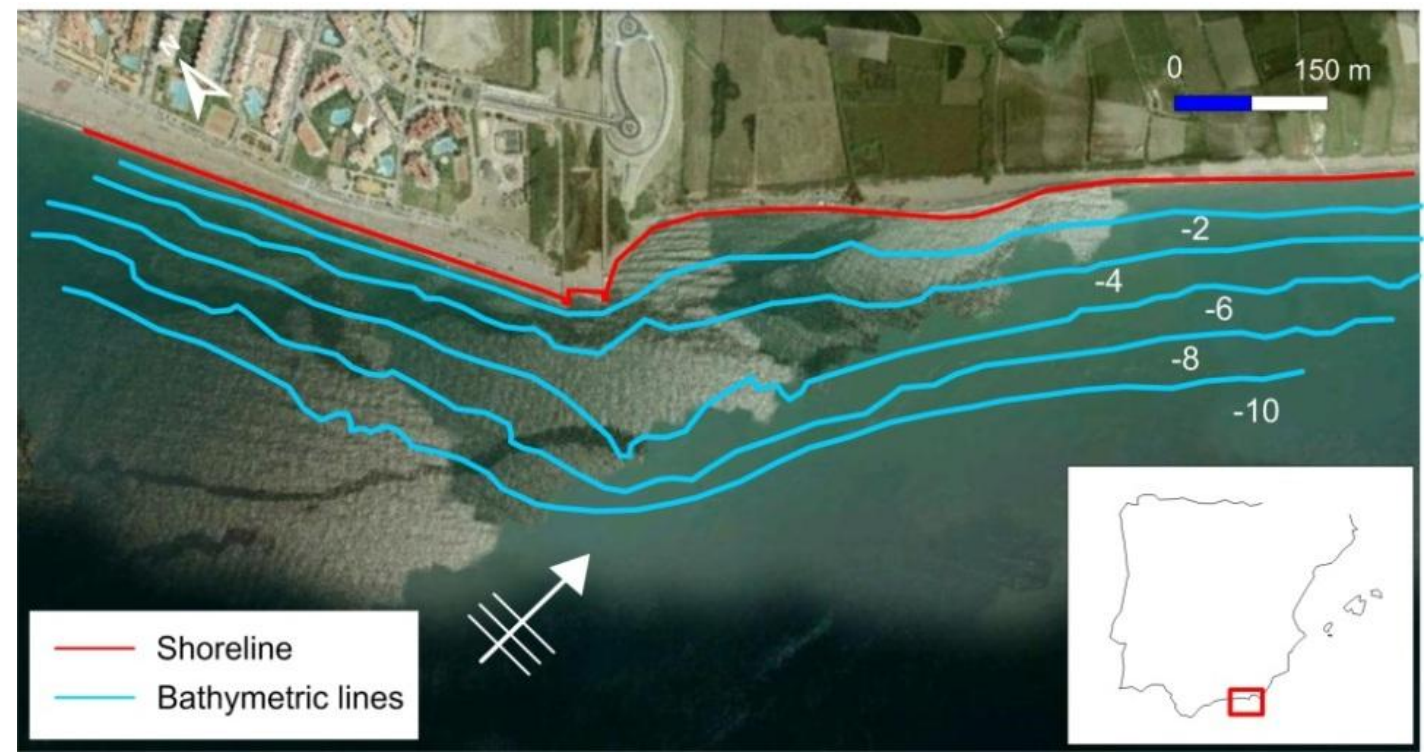

Figure 10. Plan view of the Guadalfeo river mouth, Granada, Southern Spain. Bathymetry (blue lines) and direction of the predominant waves are superposed.



Figure 11. Results obtained with the model for the Guadalfeo river mouth. 
Results seems to confirm that the combined effect of wave energy gradients due to the propagation of waves over curvilinear bathymetry and the presence of obstacles for the alongshore sediment transport, drive the formation and development of shoreline undulations in beaches adjacent to river mouths. Thus, these undulations seem to be related to erosional stretches of coast.

\section{CONCLUSIONS}

This work analyzes the influence of shoreline curvature in the morphological evolution of the coastline and the formation of shoreline undulations. A one-line type model is defined using a modified version of the Inman and Bagnold (1963) expression for the alongshore sediment transport. The model does not impose any restriction on the curvature of the shoreline. In relation to the model, the following conclusions can be drawn:

- The modified alongshore sediment transport obtained varies with the angle between the wave crests and the shoreline as well as with the surf zone width. After applying the sediment conservation equation, a term that depends on the curvature of the shoreline and another term that depends on the alongshore gradient of the surf zone width were obtained. The latter term plays an important role in the generation of shoreline undulations on curvilinear coasts.

- The model was applied to an ideal spit that resembles Doñana Spit (Gulf of Cadiz, Spain), using a simplified circular geometry with a mean alignment radius of $R \cong 2000 \mathrm{~m}$. The simulations of the shoreline evolution after five years of wave climate simulation show the formation of two largescale undulations with wavelengths and amplitudes similar to the observations. The results of the 100 simulations performed indicate that alongshore location and wavelengths of the undulations are almost deterministic, whereas their amplitudes show a random behavior.

- Preliminary results were also obtained for the erosional beach adjacent to the Guadalfeo river mouth (Southern Spain). It was found that the model reproduces qualitatively well the undulations observed in the downdrift part of the river mouth and the accretion on the updrift part. Thus, the combined effect of the concave-type bathymetry and the stoppage of sediment seem to generate these features in the erosive part of the river mouth. However, a more detailed study taking into account the wave variability is necessary to properly validate the model and to obtain wavelengths and amplitude closer to the observed ones.

- Unlike the instability mechanisms, the model does not require the presence of a previous perturbation of the shoreline for the formation of shoreline undulations since the curvilinear shape of the coast - and thus the existence of a gradient in wave energy conditions- is sufficient to trigger this process. However, the mechanism proposed in this article can be complementary to others such as the instability mechanism of Ashton et al. (2001). Indeed, the variations in shoreline morphology induced by the instability mechanism can generate alongshore variations in surf zone width, which can initiate this process. On the other hand, the morphology obtained with our model can provide the obliquity necessary to activate the instability mechanism.

\section{ACKNOWLEDGMENTS}

This work was funded in part by the Spanish Ministry of Science and Education (Project IMASDEi CTM2009-10520/MAR) and the Andalusian Regional Government (Projects TEP-4630 and P10RNM-6352). The work of the first author was partially funded by the Ministry of Education (Spain), Research Grant AP2009-2984.

\section{REFERENCES}

Ashton, A., Murray, A. B., and Arnoult, O. 2001. Formation of coastline features by large-scale instabilities induced by high-angle waves. Nature, Vol. 414, pp 296-300.

Ashton, A., and Murray, A. B. 2006a. High angle wave instability and emergent shoreline shapes: 1. Modeling of sand waves, flying spits, and capes. Journal of Geophysical Research, Vol. 111, F04011, doi: 10.1029/2005JF000422

Ashton, A., and Murray, A. B. 2006b. High angle wave instability and emergent shoreline shapes: 1. Wave climate analysis and comparisons to nature. Journal of Geophysical Research, Vol. 111, F04012, doi: 10.1029/2005JF000423.

Baquerizo, A., and Losada, M. A. 2008. Human interaction with large scale coastal morphological evolution. An assessment of the uncertainty. Coastal Engineering, Vol. 55, pp 569-580.

Del Valle, R., Medina, R., and Losada, M. A. 1993. Dependence of coefficient K on grain size. Journal of Waterway, Port, Coastal and Ocean Engineering, 119(5), 568. 
Díez-Minguito, M., Baquerizo, A., Ortega-Sánchez, M., Navarro, G., and Losada, M.A. 2012. Tide transformation in the Guadalquivir estuary (SW Spain) and process-based zonation. Journal of Geophysical Research, 117, C3.

Inman, D. L., and Bagnold, R. A. 1963. Littoral processes. In: The sea. Volume 3. Wiley-Interscience, New York.

Komar, P.D. 1998. Beach processes and sedimentation, $2^{\text {nd }}$ edition. Prentice-Hall, Upper Saddle River, NJ.

Longuet-Higgins, M. S. 1970. Longshore currents generated by obliquely incident sea waves, 2. Journal of Geophysical Research, 75(1), 6790-6801.

López-Ruiz, A., Ortega-Sánchez, M., Baquerizo, A., and Losada, M. A. 2012. Short and medium-term evolution of shoreline undulations on curvilinear coasts. Geomorphology, 159-160, 189-200. Elsevier B.V. doi:10.1016/j.geomorph.2012.03.026

Ozasa, H., and Brampton, A. 1980. Mathematical modelling of beaches backed by seawalls. Coastal Engineering, 4(1968), 47-63. doi:10.1016/0378-3839(80)90005-8

Petersen, D., Deigaard, R., and Fredsøe, J. 2008. Modeling the morphology of sandy spits. Coastal Engineering, Vol. 55, pp 671-684.

Pocinki, L. S. 1950. The application of conformal transformations to ocean wave refraction problems. Trans. Am. Geophys. Union, Vol. 31, pp 856-860.

Solari, S., and Losada, M. A. 2011. Non-stationary wave height climate modeling and simulation. Journal of Geophysical Research, 116(C9), 1-18. doi:10.1029/2011JC007101

USACE. 1984. Shore Protection Manual. Coastal Engineering Research Center, Government Printing Office, Washington DC

Wood, D.J., Muttray, M., and Oumeraci, H. 2001. The SWAN model used to study wave evolution in a flume. Ocean Engineering, 28, pp. 805-823 